Portland State University

PDXScholar

$1-1-2017$

\title{
Culturing Food Deserts: Recognizing the Power of Community-Based Solutions
}

\author{
Catherine Brinkley \\ University of California, Davis \\ Subhashni Raj \\ SUNY University at Buffalo \\ Megan Horst \\ Portland State University, mhorst@pdx.edu
}

Follow this and additional works at: https://pdxscholar.library.pdx.edu/usp_fac

\section{Let us know how access to this document benefits you.}

\section{Citation Details}

Horst, M., McClintock, N., \& Hoey, L. (2017). The intersection of planning, urban agriculture, and food justice: a review of the literature. Journal of the American Planning Association, 83(3), 277-295.

This Article is brought to you for free and open access. It has been accepted for inclusion in Urban Studies and Planning Faculty Publications and Presentations by an authorized administrator of PDXScholar. Please contact us if we can make this document more accessible: pdxscholar@pdx.edu. 


\title{
Culturing Food Deserts: Recognizing the Power of Community- Based Solutions
}

\author{
CATHERINE BRINKLEY, SUBHASHNI RAJ and MEGAN HORST
}

\begin{abstract}
Food deserts, places where residents lack nearby supermarkets, have received attention from the media, academics, policy-makers, and activists. The popular policy response is to establish a new supermarket. Yet, communities who live in food deserts may already have their own well-adapted strategies to access healthy food. In this article, we argue that policy-makers all too often overlook in situ opportunities, and may even disrupt low-cost healthy food access options with supermarket interventions. We use evidence to make two main points. First, we demonstrate the limitations of focusing on food deserts when interpreting diet-related health disparities. By conducting a US national county-level multi-variable spatial regression analysis of socio-economic status, built environment and food environment factors, we determine that diet-related health outcomes do not clearly correlate with supermarket access. Instead, health outcomes are most strongly associated with income and race. This suggests that interventions to improve healthy eating should begin with a focus on anti-poverty. Second, we identify alternative paths, beyond supermarkets, to healthy food access through a literature review. We ground-truth our findings with interviews from Public Health and Planning Department officials in seventeen counties with a high percentage of the population living in a food desert, but low levels of diet-related disease. Our research suggests new avenues for research and financing centred around existing community-based practices of established food banks and farm-to-market opportunities.
\end{abstract}

This research shifts the conversation on food desert classification and supermarket intervention to supporting already existing, prevalent, and well-adapted community efforts. The starting point for this conversation is a critique of the term, associated methodology, and various policy responses to 'food deserts'. The term 'food desert' originated in the early 1990s to describe lack of nearby affordable, healthy food retail (Cummins and Macintyre, 2002, p. 2115). The term successfully drew attention to the spatial injustice of the food system, where more sparsely populated or low-income communities did not have the purchasing power to sustain a supermarket business model. A review of forty-nine food desert studies provides evidence that lack of a supermarket ${ }^{1}$ compounds individual disadvantages in the ability to procure a healthy diet (Beaulac et al., 2009). Food is generally more 'expensive and relatively unavailable' (Cummins and Macintyre, 2002, p. 2115) leading to fewer healthy food options (Beaulac et al., 2009) and quantified negative diet-related health outcomes, including obesity and diabetes (Larson et al., 2009; Morland et al., 2006). More recently, scholars 
and public agencies have attempted to operationalize the food desert term through mapping and measurement. An example exists with the Food Atlas project of the United States Department of Agriculture (USDA), which defines a food desert as an area without a supermarket within 1 or 10 miles for urban and rural areas respectively (USDA, 2015). According to the USDA, 23.5 million Americans live in food deserts.

We argue that the food desert term is imprecise. First, the research and professional community often casually conflates spatial and other, perhaps more important, factors of access. For example, Drewnowski et al. (2014) find that in Seattle and Paris, two cities with different built and food environments, physical proximity to supermarkets was not predictive of obesity, whereas the following factors were: income levels, surrounding property values, and preferences for shopping at lower-cost stores. The focus on geographic proximity to supermarkets also reduces attention to explanatory variables related to power structures, such as race and income, which are rarely considered in models. Indeed, a growing number of studies find socio-economic factors to be significant predictors of health conditions compared to factors measuring built and food environments (Drenowski et al., 2014; Raj et al., 2016). The result is that work on food deserts too often 'bounds health problems within low-income communities' (Bedore, 2010), disregards the agency of such communities to generate alternative responses that deserve support, and ignores the policies and actors which shape disparities in food systems and accessibility (Shannon, 2014).

Second, the food desert term is far too narrow in its focus on supermarket retail. The term 'desert' often implies a lack of life, though biologists are apt to point out that the desert biome contains thriving ecosystems if you know how to look for them. Emphasis on measuring proximity to supermarkets ignores other sources of food in neighbourhoods and people's resourcefulness. Food deserts may have their own well-adapted systems of street food (Ammerman, 2012), smaller supermarkets (Raja et al., 2008), farmers' markets (Larsen and Gilliland, 2009) and urban gardens (Wang et al., 2014). By focusing myopically only on supermarkets in the food environment, the term misses other important sources of food in communities including unhealthy food options, such as fast food vendors. To this end, a recent review of sixteen studies finds that fast food consumption correlates with obesity (Rosenheck, 2008). Another review of forty articles finds that fast food restaurants are more prevalent in lowincome and ethnic neighbourhoods (Fleischhacker et al., 2011).

Practice mirrors the above flaws in research. For example, the Robert Wood Johnson Foundation award winning County Health Rankings \& Roadmaps tool includes a variable 'healthy food access', which measures spatial proximity to a supermarket. While subtle, use of 'food deserts' as a healthy food indicator arguably perverts policy-oriented results by overlooking spatial proximity to other healthy food sources as well as economic barriers to access. Because the data for dietrelated health are primarily framed around supermarket access, it is no wonder that the chief policy response lies in publically-funded supermarket financing. Chrisinger (2016) reviewed 126 new supermarket financing initiatives over the past decade, finding that 80 per cent use federal public funding. A broad range of literature has documented that although new supermarkets can help alleviate food insecurity in some contexts (Cummins et al., 2005), more often than not, new supermarkets alone are insufficient for health behaviour change (Morland et al., 2006; Wang et al., 2007; Larson et al., 2009; Walker et al., 2010; Sadler et al., 2013; Cummins et al., 2014; Elbel et al., 2015; Fuller et al., 2015; Dubowitz et al., 2015). Complicating matters, many people do not shop at their closest stores (Drewnowski et al., 2012; Cannuscio et al., 2014). The failure of supermarket interventions is compounded by several docu- 
mented cases where communities resist the use of eminent domain to acquire land and public funds to finance supermarket interventions (Sibilla, 2013; Horst et al., 2016). New methods of promoting healthy food access are needed.

Instead of focusing on supermarkets, we argue that it would be more empowering to engage communities in a conversation about what they are already doing that works, and be open to a wide range of possibilities to scale such ventures. By overlooking residents' other means of sourcing healthy food, policymakers may unintentionally cause further injustices in the local food system or miss an opportunity to augment an already existing low-cost locally-based option, such as healthy street food vending (Brinkley et al., 2013). We aim to expose such options for health with the research below.

\section{Methods}

The goal of our research methods are twofold. First, we build from the above literature review from the public health and planning disciplines by conducting a quantitative analysis of diet-related health outcomes in relation to socio-economic indicators and the percentage of the population living in food desert conditions. The multivariate statistical regression analysis is intended to highlight the importance of explicitly considering power dynamics that manifest in the built environment and food systems, and thereby impact individual health. As we suggest in the literature review, we suspect that proximity to a supermarket is not a very powerful indicator of poor diet-related health outcomes, and that socio-economic characteristics are more tightly linked. The analysis emphasizes that areas that are food deserts but have low rates of poverty are just as likely to have positive health outcomes. Second, the regression analysis allowed us to identify outlier case studies. To better understand why food deserts are not consistently related to poor health outcomes, we interviewed public officials in outlier counties. The case studies allow us to triangulate our regression findings, identify potential omitted variables of importance, and explore sorting or eco-logical fallacies (Robinson, 1950) where group or spatial correlations of the average are misinterpreted at the level of individuals. In sum, this mixed methods a proach highlights how communities achieve better than expected diet-related health in the food desert context, allowing us to consider scaling up and out such practices as alternative interventions to supermarket financing. Our methods are discussed in greater detail below.

\section{Multi-Variable Regression Analysis}

We employ a cross-sectional research design to study the effect of 'food desert' conditions, socio-economic and built environment factors on obesity and diabetes (health outcomes) in 3,142 counties in the United States. Countylevel secondary data from the Centers for Disease Control and Prevention (CDC), the USDA Food Environment Atlas and USDA's Economic Research Service ${ }^{2}$ provide estimates for the prevalence of diagnosed adult diabetes and obesity. The Rural variable is bivariate and denotes counties that are more urban (1-3) or rural (4-9) in nature, based on urbanization and adjacency to a metro area represented in Rural-Urban Continuum Codes (RUCC; Butler and Beale, 1990). Obesity is measured as the percentage of adults in a county who report BMI >= 30, while diabetes is the percentage of people diagnosed with diabetes in a county. Explanatory variables encompass socio-economic characteristics along with the food and built environment (table 1). Descriptive statistics are reported in table 1. Not all explanatory variables tested were used in the regression analysis. For example, we considered childhood poverty and educational levels, but these variables correlate with median household income (MHHI), and they increase multicollinearity in the model.

Nationally, about 30 per cent of adults are 
Table 1. County-level descriptive statistics. The Supermarket proximity variable (PROX) uses the USDA definition in measuring the percentage of the population that is further than one mile from a supermarket in urban counties and more than 10 miles $(16 \mathrm{~km})$ from a supermarket in rural counties.

\begin{tabular}{|c|c|c|c|c|c|c|}
\hline $\begin{array}{l}\text { Category } \\
\text { Name }\end{array}$ & Variable & $\begin{array}{l}\text { Short } \\
\text { Variable } \\
\text { Name }\end{array}$ & Units & $\begin{array}{l}\text { Descriptive } \\
\text { Statistics }\end{array}$ & $\begin{array}{l}\text { Data } \\
\text { Year }\end{array}$ & $\begin{array}{l}\text { Data } \\
\text { Source }\end{array}$ \\
\hline \multirow[t]{2}{*}{$\begin{array}{l}\text { Health } \\
\text { Outcome }\end{array}$} & Obesity & OB & $\begin{array}{l}\% \text { of adults that } \\
\text { report BMI }>=30\end{array}$ & $31.02 \pm 4.52$ & 2013 & $\begin{array}{l}\text { CDC County } \\
\text { level estimates }\end{array}$ \\
\hline & Diabetes & DB & $\begin{array}{l}\% \text { of people } \\
\text { diagnosed with } \\
\text { diabetes }\end{array}$ & $11.24 \pm 2.49$ & 2013 & \\
\hline \multirow[t]{7}{*}{$\begin{array}{l}\text { Socio- } \\
\text { economic } \\
\text { variables }\end{array}$} & $\begin{array}{l}\text { Median } \\
\text { household } \\
\text { income }\end{array}$ & MHHI & US\$ & $43144.87 \pm 10742.29$ & 2010 & \\
\hline & White & WH & Percentage & $78.29 \pm 19.89$ & 2010 & \\
\hline & $\begin{array}{l}\text { African } \\
\text { American }\end{array}$ & $\mathrm{AA}$ & Percentage & $8.75 \pm 14.42$ & 2010 & \\
\hline & No vehicle & TRP & Percentage & $3.15 \pm 3.21$ & 2010 & \\
\hline & $\begin{array}{l}\text { Lack of } \\
\text { supermarket } \\
\text { proximity }\end{array}$ & PROX & Percentage & $23.56 \pm 20.25$ & 2010 & \\
\hline & $\begin{array}{l}\text { Convenience } \\
\text { stores }\end{array}$ & CONV & $\begin{array}{l}\text { No. of } \\
\text { convenience } \\
\text { stores per } \\
1,000 \text { persons }\end{array}$ & $0.59 \pm 0.31$ & 2012 & $\begin{array}{l}\text { USDA Food } \\
\text { Environment } \\
\text { Atlas }\end{array}$ \\
\hline & $\begin{array}{l}\text { Specialty } \\
\text { stores* }^{*}\end{array}$ & SPC & $\begin{array}{l}\text { No. of specialty } \\
\text { stores per } 1,000 \\
\text { persons }\end{array}$ & $0.05 \pm 0.07$ & 2012 & \\
\hline \multirow[t]{3}{*}{$\begin{array}{l}\text { Food } \\
\text { environment }\end{array}$} & $\begin{array}{l}\text { Fast food } \\
\text { restaurants }\end{array}$ & FFR & $\begin{array}{l}\text { No. of fast food } \\
\text { restaurants per } \\
1,000 \text { persons }\end{array}$ & $0.58 \pm 0.30$ & 2012 & \\
\hline & $\begin{array}{l}\text { Full service } \\
\text { restaurants }\end{array}$ & FSR & $\begin{array}{l}\text { No. of full } \\
\text { service } \\
\text { restaurants per } \\
1,000 \text { persons }\end{array}$ & $0.79 \pm 0.59$ & 2012 & \\
\hline & $\begin{array}{l}\text { Farmers } \\
\text { markets }\end{array}$ & FRM & $\begin{array}{l}\text { No. of farmers } \\
\text { markets per } \\
1,000 \text { persons }\end{array}$ & $0.05 \pm 0.09$ & 2013 & \\
\hline \multirow[t]{2}{*}{$\begin{array}{l}\text { Built } \\
\text { environment }\end{array}$} & $\begin{array}{l}\text { Recreational } \\
\text { facilities }\end{array}$ & $\mathrm{RC}$ & $\begin{array}{l}\text { No. of } \\
\text { recreational } \\
\text { facilities per } \\
1,000 \text { persons }\end{array}$ & $0.07 \pm 0.07$ & 2012 & \\
\hline & $\begin{array}{l}\text { Metropolitan } \\
\text { or non- } \\
\text { metropolitan }\end{array}$ & MT & $\begin{array}{l}\text { Dichotomous } \\
\text { variable }\end{array}$ & $0.37 \pm 0.48$ & 2013 & $\begin{array}{l}\text { USDA } \\
\text { Economic } \\
\text { Research } \\
\text { Service RUCC } \\
\text { codes }\end{array}$ \\
\hline
\end{tabular}

Note: * Specialty stores include retail primarily engaged in selling specialized lines of food, such as bakeries, meat and seafood markets, dairy stores, and produce markets. 
considered obese, and 11 per cent of the population has been diagnosed with diabetes (table 1 ). The average median household income is $\$ 43,144$. About 78 per cent of the population identifies as white, with 9 per cent identifying as African American. On average, 3 per cent of the population lacks a car and lives more than 1 mile $(1.6 \mathrm{~km})$ from a supermarket. Another 24 per cent of the population lives far away from a supermarket, defined for urban populations as living more than one mile from a supermarket, and for rural areas as more than 10 miles $(16 \mathrm{~km})$ from a supermarket. There are on average more convenience stores $(0.59)$ than specialty stores (0.05) and farmers markets (0.05) per 1,000 people in the county. Similarly, there are more full service restaurants (0.79) than fast food restaurants $(0.58)$ or recreational facilities (0.07) per 1,000 people. Thirty-seven per cent of counties are metropolitan counties.

We ran a two-level generalized linear mixed effects model with a Gaussian distribution and identity link to test the effect of socio-economic, food, and built environment measures on diabetes and obesity at the county level, accounting for state level clustering using Stata/IC version 13.1 software. The two-level generalized linear mixed effects model was fitted using the step-wise process outlined by Tabachnick et al. (2001). Model fit diagnostics (deviance, AIC and BIC) were estimated and examined. Multicollinearity was addressed by dropping interaction terms, such as the race variable 'white' (WH). Heteroscedasticity was controlled by employing robust standard errors. We tested the covariance structures available in STATA for the final model. The standard covariance structure was the best suited for our models. Normality was tested by plotting the normal probability plots and histogram of the residuals and looking at the scatter plots of the standardized residuals. Our final models are specified below:

Equation 1: $\mathrm{Y}_{O B_{i j}}=\gamma_{00}+\gamma_{1}$ PROX + $\gamma_{2} M H H I+\gamma_{3} A A+\gamma_{4} C O N V+\gamma_{5} S P C+$

$$
\begin{aligned}
& \gamma_{6} F S R+\gamma_{7} F F R+\gamma_{8} F R M+\gamma_{9} R C+ \\
& \gamma_{10} T R P+\gamma_{11} \text { Rural }+\zeta_{0 i}+\zeta_{1 i}(\mathrm{MHHI})+\varepsilon_{i j} \\
& \text { Equation } 2: \mathrm{Y}_{D B_{i j}}=\gamma_{00}+\gamma_{1} P R O X+ \\
& \gamma_{2} \text { MHHI }+\gamma_{3} A A+\gamma_{4} C O N V+\gamma_{5} S P C+ \\
& +\gamma_{6} F S R+\gamma_{7} F F R+\gamma_{8} F R M+\gamma_{9} R C+ \\
& \gamma_{10} T R P+\gamma_{11} \text { Rural }+\zeta_{0 i}+\zeta_{1 i}(\mathrm{MHHI})+\varepsilon_{i j}
\end{aligned}
$$

$\mathrm{Y}_{O B_{i j}}$ and $\mathrm{Y}_{D B_{i j}}{ }$ are the dependent variables obesity and diabetes, respectively, for counties nested in states. The random effects portion of the model contains $\zeta_{0 i}$, the random intercept; $\zeta_{1 i}(\mathrm{MHHI})$, the random slope; and $\varepsilon_{i j}$ is the county level error term for the model. Fixed effect terms are found in table 1.

\section{Case Selection}

We focus our interviews on outlier counties to identify spatial and policy measures that may engender diet-related health in the food desert context. Based on the literature, outlier counties would be those where despite food desert conditions, better than average health outcomes (obesity and diabetes) are found. These are interesting cases because they disprove the assumption that the presence of a food desert is linked with poor health outcomes. Some researchers hypothesize that rural populations have unique coping mechanisms to deal with this poor geographic access (Smith and Morton, 2009). Such 'uniqueness' to cope has not been evaluated. Using the list function in STATA, we identified the counties that had a high prevalence of the population in food desert areas and yet displayed low levels of obesity and diabetes, based on the standard deviation from the means in those variables (see table 2). The selection process took into account the RUCC yielding seven urban and fifteen rural cases. Our inquiry calls attention to outliers as a means of understanding planning and policy in places that at a macro level would be considered a food desert and should have higher obesity and diabetes rates. Public officials in each of the 
selected counties were contacted for semistructured interviews.

\section{Interviews with Representatives in Select Counties}

The interviews serve three purposes. First, interviewees helped verify the quantitative findings by explaining whether the census data matched local understanding of the county. Second, interviewees provided insight into the spatial arrangement of the built environment, food environment and population characteristics of the counties to better understand why counties lack supermarkets. Finally, interviewees identified alternative pathways to healthy food in their counties. We specifically asked about food retail options, policy interventions, and the presence and activities of organizations such as food banks.

Following a protocol approval from the
University of California, Davis Internal Review Board, interviews were solicited by email and phone with County Public Health and Planning Departments from twenty-two counties (see appendix for interview solicitation and format). Interviews were completed for eight counties and only one representative interview was obtained for nine other counties (table 2, figure 1). Fifteen-minute phone interviews with semi-structured interview questions were recorded, transcribed and coded for seventeen counties. We triangulated interview material by soliciting interviews from multiple county officials and verifying findings with secondary literature through document review and web searches.

\section{Limitations}

The mixed-methods model seeks to triangulate quantitative and qualitative findings,

Table 2. Case study counties with a high proportion of the population living in a food desert (PROX), but better-than-expected diet-related health outcomes. Rural-urban continuum codes (RUCC) denote counties that are more urban (1) or rural (9) in nature based on degree of urbanization and adjacency to a metro area.

\begin{tabular}{llllllrl}
\hline State & County & Obesity $(\%)$ & $\begin{array}{l}\text { Diabetes } \\
(\%)\end{array}$ & PROX $(\%)$ & $\begin{array}{l}\text { Population in } \\
\text { Poverty }(\%)\end{array}$ & Population & RUCC Code \\
\hline Alaska & Denali* & 27.0 & 5.8 & 18.5 & 12.8 & 1,867 & 8 \\
Colorado & Costilla & 21.9 & 8.3 & 55.3 & 25 & 3,518 & 9 \\
Colorado & Crowley* & 21.6 & 6.0 & 30 & 28.3 & 5,322 & 8 \\
Colorado & Hinsdale* & 20.5 & 6.6 & 26.8 & 7.5 & 813 & 9 \\
Colorado & Lake* & 17.5 & 5.4 & 26.5 & 12.2 & 7,306 & 6 \\
Colorado & Mineral & 18.1 & 6.8 & 22.5 & 6.8 & 721 & 9 \\
Colorado & Saguache & 19.9 & 7 & 51.5 & 25.1 & 6,208 & 9 \\
Colorado & San Juan* & 19.3 & 6.7 & 19.4 & 16.5 & 692 & 9 \\
Colorado & Washington & 23.2 & 6.5 & 19.1 & 12.9 & 4,803 & 9 \\
Idaho & Boise* & 22.4 & 9.6 & 30.6 & 15.9 & 6,795 & 2 \\
Kansas & Riley & 23.8 & 5.6 & 21.7 & 22.3 & 75,394 & 3 \\
Montana & Daniels* & 25.5 & 9.0 & 34.9 & 6.7 & 1,791 & 9 \\
Montana & Granite & 29.0 & 9.1 & 21.9 & 12.8 & 3,138 & 8 \\
New Mexico & Dona Ana & 23.6 & 7.4 & 20.9 & 27.8 & 213,460 & 3 \\
New Mexico & Taos & 17.4 & 7.7 & 21.1 & 23.7 & 33,035 & 7 \\
Texas & Brazos & 28.4 & 7.6 & 18.1 & 29.3 & 203,164 & 3 \\
Virginia & Rappahannock & 27.2 & 11.7 & 18.7 & 10.7 & 7,478 & 1 \\
\hline
\end{tabular}

Note: * denotes only one interview. 


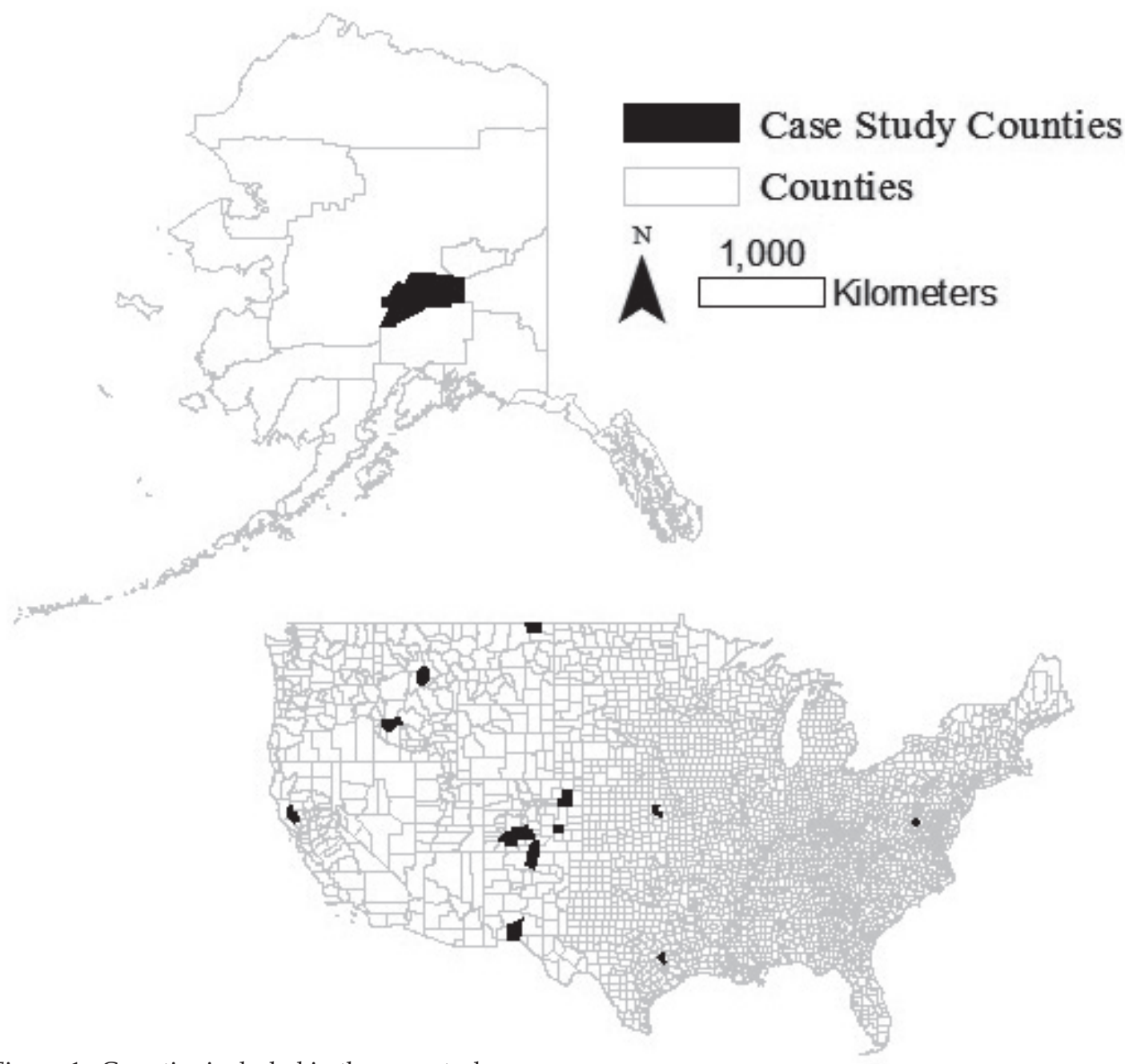

Figure 1. Counties included in the case study.

but is limited in available national-level data, the county unit of analysis, practitioner understandings of their counties, and limited case studies. As the case studies revealed, the model omits important demographic variables, such as length of residence in the county, as well as food environment variables, such the prevalence of roadside stands, and built environment variables, such as hiking trails. Indeed, diet-related health outcomes are the result of many cumulative decisions at the individual-level. Countylevel data may be too large a scale to pick up spatial variations in socio-economic groupings, the built environment or the food environment. Moreover, obesity and diabetes health outcomes are multi-causal. Thus, the modest goal of this regression analysis is to explore the broad usefulness of socio-economic, built and food environment variables as predictive in comparison to one another. In particular, recent literature reviewed in the introduction indicates that research and practice often omit explanatory variables related to power structures, such as race and income.

Interviews in study counties seek to 
correct for the model's lack of longitudinal data, omitted variables and sorting effects as populations move. Yet, a larger sample of case studies is needed to further explain and verify quantitative findings. The cases identified tend to be skewed regionally (figure 1). For example, the case selection yields more rural than urban counties because food deserts are more likely to be located in rural areas. According to the USDA, food deserts are distributed among 448 counties in the United States, of which 98 per cent are rural. Despite using an indicator that highlights the lack of supermarkets in rural areas, there is a puzzling over emphasis on urban areas in food desert research and policy responses (McEntee and Agyeman, 2010; Walker et al., 2010). Since rural counties are underrepresented in food systems research the skewness in the case selection is important to ensure rural county considerations are factored in the qualitative analysis. Though this study focuses across urban and rural counties, future research may be needed to drill down to smaller geographic levels. Companion pieces outside of the US can determine external validity internationally.

\section{Findings and Discussion}

Across models, socio-economic predictors showed similar signs for predicting dietrelated health outcomes when compared to built and food environment variables. Every $\$ 10,000$ more in median household income is associated with 1 per cent less obesity and 0.71 per cent less diabetes. Every percentage increase in the proportion of the African American population correlates with greater prevalence of obesity (0.08 per cent) and diabetes ( 0.03 per cent). Our findings are supported by recent literature that emphasizes the importance of including income and race variables in understanding health (Drenowski et al., 2014; Raj et al., 2016). It is important to note that in many places in the US, race and income are highly spatially correlated (Downey, 1998) in part due to land-use policies, such as redlining, in which mortgages are denied in certain locations based on skin colour. The legacy of explicitly racist policies has left longterm and on-going disparities across food and built environments (Eisenhauer, 2001). Logically, the quality and quantity of food and built environment features in a county may be mediated by income levels, where higher income communities cultivate more opportunities to support healthy lifestyles. This may explain the impact of recreational facilities. For an additional recreational facility per 1,000 persons there is 4.19 per cent less obesity and 1.08 per cent less diabetes. The descriptive data indicate the availability of recreational facilities to be sparse and highly variable among the counties. The percentage of the population with lack of car access and the rural nature of the county were not predictive.

In contrast, the effects of food and built environment variables are less predictive across both diet-related health outcomes. Proximity to a supermarket, while statistically significant, is not practically meaningful given the small coefficient sizes. A percentage increase in the number of people who do not live in close proximity to a supermarket is associated with 0.01 per cent less obesity and a 0.00 per cent decrease in diabetes. While a 1 per cent lower incidence of obesity strongly correlates with two more full service restaurants and one farmers' market per 500 residents, the effects of these food environment variables are insignificant on diabetes outcomes. Instead, fewer convenience stores and more fast food restaurants are associated with lower diabetes incidences. For example, for every additional fast food restaurant per 1,000 people, counties have a 0.65 per cent less diabetes. Every convenience store per 1,000 people correlations with 0.75 per cent more obesity and 0.79 per cent more diabetes (table 3).

Because built environment obstacles, such as car access, were not predictive and food environment predictors were divided, we 
Table 3. Effects of food and built environment on diet-related health outcomes in the United States.

\begin{tabular}{|c|c|c|c|c|c|c|}
\hline \multirow[b]{2}{*}{ Fixed Effects } & \multicolumn{2}{|c|}{ Obesity } & \multicolumn{4}{|c|}{ Diabetes } \\
\hline & Coefficient & SE & $\mathrm{p}$-value & Coefficient & SE & $\mathrm{p}$-value \\
\hline MHHI & -1.00 & 0.096 & 0 & -0.71 & 0.079 & 0 \\
\hline African American & 0.08 & 0.011 & 0 & 0.03 & 0.004 & 0 \\
\hline No vehicle & 0.07 & 0.049 & 0.155 & 0.05 & 0.052 & 0.316 \\
\hline Supermarket proximity & -0.01 & 0.003 & 0 & 0 & 0.002 & 0.017 \\
\hline Convenience stores & 0.75 & 0.264 & 0.005 & 0.79 & 0.142 & 0 \\
\hline Specialty stores & -2.03 & 0.864 & 0.019 & -0.37 & 0.359 & 0.299 \\
\hline Full service restaurants & -1.2 & 0.235 & 0 & -0.09 & 0.071 & 0.177 \\
\hline Fast food restaurants & -0.26 & 0.291 & 0.377 & -0.65 & 0.129 & 0 \\
\hline Recreational facilities & -4.19 & 1.147 & 0 & -1.08 & 0.391 & 0.006 \\
\hline Farmers' markets & -2.17 & 0.476 & 0 & 0.1 & 0.298 & 0.729 \\
\hline Metro & -0.41 & 0.195 & 0.037 & -0.25 & 0.073 & 0.001 \\
\hline Intercept & 35.55 & 0.767 & 0 & 13.86 & 0.499 & 0 \\
\hline \multicolumn{7}{|l|}{ Random Effects } \\
\hline Level 2: Intercept & 9.32 & 2.471 & & 5.32 & 1.954 & \\
\hline MHHI & 0.24 & 0.092 & & 0.1 & 0.045 & \\
\hline Level 1: Residuals & 7.04 & 0.363 & & 1.79 & 0.089 & \\
\hline \multicolumn{7}{|l|}{ Deviance Statistics } \\
\hline Deviance & 15281.3 & & & 11037.7 & & \\
\hline AIC & 15311.3 & & & 11067.7 & & \\
\hline BIC & 15402.1 & & & 11158.4 & & \\
\hline
\end{tabular}

ascertain that socio-economic variables are more informative in understanding health. These results indicate that to provide enduring systemic changes that address disparate health outcomes, policies need to explicitly address economic access and race. In support, the level two intercepts for both models indicate significant between-state variation in median household income. State political structures confer different social values which, in turn, affect how resources are directed and distributed among communities. Indeed, income may moderate values and, in turn, influence state-level variation in regional food and health policies which alter social support, infrastructure and food policies broadly. While results (see table 3 ) indicate similar diet-related disease prevalence for urban (35.14 per cent obese, 13.61 per cent diabetic) and rural counties (35.5 per cent obese, 13.9 per cent) counties, our regression results also show that people experience their localized food systems unevenly depending on income, race and the opportunities (farmers' markets and recreational facilities) available in their communities. There is also some variation remaining between counties, indicating our model does not fully explain the complexity of diet-related health outcomes.

\section{Interview Findings}

The interviews of representatives from seventeen counties allowed us to further examine place-based and population-based characteristics that create food desert conditions and influence health outcomes. We identified the following key themes as important to better 
understanding food deserts and healthy food access: varied underlying explanatory models for the lack of supermarkets; the overlooked role of sorting; and the wide variety of strategies employed by residents and community leaders in so-called food deserts to access healthy food.

First, interview data suggest that both built environment and socio-economic factors contribute to a lack of supermarkets in the case study counties. In half the counties, existing large lot land uses, such as a military base, prison, state park or university, prohibited supermarkets from locating nearby due to the lack of sufficient open land and low customer densities. Population characteristics were given as explanations for food desert conditions in two-thirds of the counties, with explanations ranging from a lack of purchasing power due to poverty (seven counties), itinerant populations engaged in seasonal work (three counties), inaccurate census data for areas where there are undocumented populations (two counties), and more people per household in multi-generational housing leading to under-estimates of consumer base (one county). Two counties with universities indicated that students do not purchase at supermarkets, but prefer street food, fast food and restaurant venues for the convenience of ready-made food. This sentiment is echoed in a recent Atlantic article titled, 'Why Do Millennials Hate Groceries?' (Thompson, 2016).

Further, these results suggest that a nuanced understanding of the factors leading to a lack of supermarkets is necessary. In some cases, land use and purchasing power rationales ran in tandem with sparsely populated low-income communities unable to support the conventional supermarket business model. In other cases, the built environment and social networks worked to opposite ends. In one largely rural, low-income county, several wealthy residents heavily influence land-use decisions to keep the county rural and historic in character while also supporting a Michelin star restaurant. The wealthier community intentionally prevented large brand-name supermarkets from locating in the county to protect smaller-scale, locally managed stores from competition. Thus, the built environment is mediated through social and economic control, a finding supported by the regression models.

Second, interviewees attributed better than expected health outcomes to the effects of sporting and physical activity levels over the food environment. Physical labour and outdoor lifestyles were cited as reasons for better-than-expected health outcomes in ten out of the thirteen counties that responded to this question, with the physical environment contributing recreational opportunities in half of the counties. In three counties, interviewees believed that the presence of universities or military bases gave the population a more favourable physical fitness average than might have otherwise been the case. Also notable is that the state of Colorado is overrepresented amongst the outlier case counties. Colorado has ranked as the fittest state in the union for the past decade according to the National Centers for Disease Control and Prevention, and has the lowest rates of obesity and adult diabetes and second-lowest rate of hypertension (2016). Interviewees from Colorado counties indicated that the better than expected dietrelated health outcomes could be due to self-selection, as health-motivated residents choose to live near recreational opportunities afforded in the mountains, such as hiking and skiing, or work directly with resort facilities. Due to a lack of health services, many residents with health conditions choose to relocate to lower altitudes, further skewing the place-based health outcomes with residents self-sorting as fitter, younger residents moving in and older, less healthy residents move away to be closer to health services. Respondents believed these factors were more influential than the food environment on positive health outcomes.

Third, residents living in food deserts use a variety of strategies to access food. Interviewees from all the counties reported 
bulk shopping at large stores outside the community as the primary mode of food procurement. Residents also used smallerscale, local supermarkets in the county for staple items. Only two of the counties had public transit, and none had formal ridesharing programmes. Several counties used social media networks, like facebook, to solicit ride-sharing and to pick up groceries or medications for community members. Because supermarket shopping is the primary form of obtaining food, many scholars would say that a focus on food deserts and lack of supermarkets is warranted. Our results, however, point to other highly prevalent food acquisition practices when such convenience is absent. About half the counties had established farmers' markets or roadside farm stands, and all but two had seasonal farm-to-market opportunities. For example, the largely secluded ethno-religious Hutterite farming community comes to the main town in Daniels County, Montana weekly during the growing season to sell produce, baked goods, eggs and milk from the back of their truck. Amish farmers in other parts of the country are similarly engaged in direct marketing practices (Kraybill et al., 2010; Brinkley, 2017). All but one county had some form of road-side vending, with the majority being seasonal, fresh produce trucks that source from local farms or produce terminals and park temporarily for sales. Gardening was a prevalent practice in all but three counties. In locales where growing seasons were short and altitudes prevented vegetable and fruit growing, backyard poultry were popular. One-third of the counties reported hunting and gathering as important methods of supplementing their diets.

All but two counties had food banks, with varying degrees of involvement in fresh food purchasing. In comparison, none of the counties reported a food policy council. Food bank management varied: some were run through non-profits, others through churches, public agencies, or combinations of the above. The central role of the food bank in food desert conditions represents a largely overlooked mode of intervening in healthy food policy. Many food banks were heavily embedded in publicly-run programmes. For example, public agencies run the federal food subsistence programmes (Women Infant and Children and Supplemental Nutritional Assistance) while coordinating free breakfasts and lunches through public schools in combination with food banks. In one largely rural, low-income county, several wealthy residents 'single-handedly' finance healthy food options, such as the school lunch and weekend backpack of healthy food programme run through the local food bank.

The counties were engaged in a variety of interventions to increase access to healthy food and to enhance healthy eating. Counties reported involvement from public, private, and non-profit agencies across communityled efforts. University extension offered master gardener, $4 \mathrm{H}$, and food preservation courses to help stretch home-grown supplies through the winter months for selfprovisioning. Private companies, like Alison's Pantry and local grocery co-ops, sold bulk meals directly to homes in two Colorado counties. An example of the community-led efforts which combine government, nonprofit and business institutions is exemplified in San Juan County, Colorado, where a local restaurant coordinates with the food pantry run by the Catholic Church and the Area Agency for Aging to run a weekly senior dinner.

\section{Conclusion}

This research asks researchers and policymakers to move beyond the narrow focus on supermarket proximity and acknowledge the forces shaping the spatial inequities in healthy, affordable food access, namely, race and poverty. As the regression model shows, purchasing power attributes, represented by median household income, more strongly correlate with diet-related outcomes than other factors, including supermarket proximity. 
As such, anti-poverty measures, such as minimum wage raises, and price support for farmers' markets (Young et al., 2013) are supported models for improving diets for low-income residents. Such policies will support low-income people regardless of how close they live to a supermarket. The case studies emphasize that food deserts differ vastly in their underlying physical, social and policy characteristics, making findings from various studies on food deserts difficult to generalize beyond the need to give communities the chance to innovate as suits their needs.

In conclusion, it is imperative that future research explicitly considers variables related to power structures in the food system, namely income and race. These variables are all too often left out, and directly affect the research and policy recommendations made. There are many pathways to healthy food access. Where supermarkets are lacking, residents tend to travel long distances and coordinate within their community for bulk buying while relying on local smaller-scale supermarkets for staple items. The commonalities among the counties point to farmto-market, self-provisioning and food banks as strategies for food acquisition. Future research can help examine the potential of such avenues to supplement food budgets, and how such efforts can be supported or scaled-up to impact health outcomes.

\section{NOTES}

1. We intentionally use the word supermarket, not grocery store for two main reasons. First, it is the term used by the USDA in their definition of food deserts. Second, as part of our argument in the article, the focus on supermarkets, which are larger in floor area and sales volume, can overlook the presence of smaller stores with a variety of ownership models.

2. There are 3,143 counties/equivalent counties in the United States (limited to the 50 states) 3,007 counties, 16 Boroughs in Alaska, 11 Census Areas in Alaska (for areas not organized into Boroughs by the State), 64 Parishes in Louisiana, 42
Independent Cities (1 in Maryland, 1 in Missouri, 1 in Nevada, and the remainder in Virginia), 1 District - the Federal District or District of Columbia. We omit one US county (Kalawao, Hawaii) which did not have median household income data.

\section{REFERENCES}

Ammerman, A.S. (2012) Accessing nutritious food in low-income neighborhoods. North Carolina Medical Journal, 7(5), pp. 384-384.

Beaulac, J., Kristjansson, E. and Cummins, S. (2009) A systematic review of food deserts, 1966-2007. Preventing Chronic Disease, 6(3), A105.

Bedore, M. (2010) Just urban food systems: a new direction for food access and urban social justice. Geography Compass, 4(9), pp. 1418-1432.

Brinkley, C. (2017) Visualizing the social and geographical embeddedness of local food systems. Journal of Rural Studies, 54, pp. 314-325.

Brinkley, C., Chrisinger, B. and Hillier, A. (2013) Tradition of healthy food access in low-income neighborhoods: price and variety of curbside produce vending compared to conventional retailers. Journal of Agriculture, Food Systems, and Community Development, 4(1), 155-169.

Butler, M. A. and Beale, C.L. (1990) Rural-Urban Continuum Codes for Metro and Nonmetro Counties. No. 9028. Washington DC: US Department of Agriculture, Economic Research Service, Agriculture and Rural Economy Division.

Cannuscio, C.C., Hillier, A., Karpyn, A. and Glanz, K. (2014) The social dynamics of healthy food shopping and store choice in an urban environment. Social Science \& Medicine, 122, pp. 13-20.

Chrisinger, B.W. (2016) Taking Stock of New Supermarkets in Food Deserts: Patterns in Development, Financing, and Health Promotion. Bedminster, NJ: The Investment Center. Available at: http:// www.frbsf.org/community-development/ publications/working-papers/2016/august/newsupermarkets-in-food-deserts-developmentfinancing-health-promotion/.

Cummins, S. and Macintyre, S. (2002) A systematic study of an urban foodscape: the price and availability of food in greater Glasgow. Urban Studies, 39(11), pp. 2115-2130.

Cummins, S., Findlay, A., Petticrew, M. and Sparks, L. (2005) Healthy cities: the impact of food retail-led regeneration on food access, choice and retail structure. Built Environment, 31(4), pp. 288-301. 
Cummins, S., Flint, E. and Matthews, S.A. (2014). New neighborhood grocery store increased awareness of food access but did not alter dietary habits or obesity. Health Affairs, 33(2), pp. 283-291.

Downey, L. (1998) Environmental injustice: is race or income a better predictor? Social Science Quarterly, 79(4), pp.766-778.

Drewnowski, A., Aggarwal, A., Hurvitz, P.M., Monsivais, P. and Moudon, A.V. (2012) Obesity and supermarket access: proximity or price? American Journal of Public Health, 102(8), pp. e74-e80.

Drewnowski, A., Moudon, A.V., Jiao, J., Aggarwal, A., Charreire, H. and Chaix, B. (2014) Food environment and socioeconomic status influence obesity rates in Seattle and in Paris. International Journal of Obesity, 38(2), pp. 306-314.

Dubowitz, T., Ghosh-Dastidar, M., Cohen, D.A., Beckman. R., Steiner, E.D., Hunter, G.P. et al. (2015) Diet and perceptions change with supermarket introduction in a food desert, but not because of supermarket use. Health Affairs, 34(11), pp. 1858-1868.

Eisenhauer, E. (2001) In poor health: supermarket redlining and urban nutrition. GeoJournal, 53(2), pp. 125-133.

Elbel, B., Moran, A., Dixon, L.B., Kiszko, K., Cantor, J., Abrams, C. et al. (2015) Assessment of a government-subsidized supermarket in a high-need area on household food availability and children's dietary intakes. Public Health Nutrition, 18(15), pp. 2881-2890.

Fleischhacker, S.E., Evenson, K.R., Rodriguez, D.A. and Ammerman, A.S. (2011) A systematic review of fast food access studies. Obesity Reviews, 12(5), pp. e460-e471.

Gundersen, C, Waxman Fy, Fngelhard, E., Satoh, A. and Chawla, N. (2013) Map the meal gap 2013: food insecurity estimates at the county level. Feeding America. Available at: http:// www.feedingamerica.org/hunger-in-america/ our-research/map-the-meal-gap/2013/map-themeal-gap-2013-exec-summ.pdt.

Fuller, D., Engler-Stringer, R. and Muhajarine, N. (2015) Examining food purchasing patterns from sales data at a full-service grocery store intervention in a former food desert. Preventitive Medicine Reports, 2, pp.164-169.

Horst, M., Raj, S. and Brinkley, C. (2016) Getting outside the supermarket box: alternatives to 'food deserts'. Progressive Planning, 207(Spring), pp. 9-12.

Kraybill, D.B., Nolt, S.M. and Wesner, E.J. (2010)
Amish enterprise: the collective power of ethnic entrepreneurship. Global Business and Economics Review, 12(1/2), pp. 3-20.

Larsen, K. and Gilliland, J. (2009) A farmers' market in a food desert: evaluating impacts on the price and availability of healthy food. Health E Place, 15(4), pp.1158-1162.

Larson, N., Story M. and Nelson M. (2009) Neighborhood environments: disparities in access to healthy foods in the U.S. American Journal of Preventive Medicine, 36(1), pp.74-81.

McEntee, J. and Agyeman, J. (2010) Towards the development of a GIS method for identifying rural food deserts: geographic access in Vermont, USA. Applied Geography, 30(1), pp.165-176.

Morland, K., Diez Roux, A.V., Wing S. (2006) Supermarkets, other food stores, and obesity: the atherosclerosis risk in communities study. American Journal of Preventive Medicine, 30(4), pp. 333-339.

National Centers for Disease Control and Prevention (2016) Adult Obesity Maps. Available at: https://www.cdc.gov/obesity/data/prevalencemaps.html.

Raj, S., Raja, S. and Dukes, B. (2016) Beneficial but constrained: role of urban agriculture programs in supporting healthy eating among youth. Journal of Hunger $\mathcal{E}$ Environmental Nutrition, 12(3), pp. 1-23.

Raja, S., Ma, C. and Yadav, P. (2008) Beyond food deserts measuring and mapping racial disparities in neighborhood food environments. Journal of Planning Education and Research, 27(4), pp. $469-482$.

Robinson, W.S. (1950) Ecological correlations and the behavior of individuals. American Sociological Review, 15, pp. 351-357.

Rosenheck, R. (2008) Fast food consumption and increased caloric intake: a systematic review of a trajectory towards weight gain and obesity risk. Obesity Reviews, 9(6), pp. 535-547.

Sadler, R.C., Gilliland, J.A. and Arku, G. (2013) Community development and the influence of new food retail sources on the price and availability of nutritious food. Journal of Urban Affairs, 5(4), pp.471-491.

Shannon, J. (2014) Food deserts: governing obesity in the neoliberal city. Progress in Human Geography, 38(2), pp. 248-266.

Sibilla, N. (2013) Philadelphia wants to use eminent domain to turn an artist's studio into a parking lot and supermarket. Forbes Magazine (online). Available at: http://www.forbes.com/ 
sites/instituteforjustice/2013/12/03/philadelphiawants-to-use-eminent-domain-to-turn-anartists-studio-into-a-parking-lot-and-super market/\#7c5995d28576.

Smith, C. and Morton, L.W. (2009) Rural food deserts: low-income perspectives on food access in Minnesota and Iowa. Journal of Nutrition Education and Behavior, 41(3), pp.176-187.

Tabachnick, B.G., Fidell, L.S. and Osterlind, S.J. (2001) Using Multivariate Statistics. Boston: Allyn and Bacon.

Thompson, D. (2016) Why do millennials hate groceries? The Atlantic. 2 November. Available at: https://www.theatlantic.com/business/arch ive/2016/11/millennials-groceries/506180/.

USDA (2015) Food Access Research Atlas. Available at: https://www.ers.usda.gov/data-products/ food-access-research-atlas/go-to-the-atlas/.

Walker, R.E., Keane, C.R. and Burke, J.G. (2010) Disparities and access to healthy food in the United States: a review of food deserts literature. Health and Place, 16(5), pp. 876-884.

Wang, M.C., MacLeod, K.E., Steadman, C., Williams, L., Bowie, S.L., Herd, D. et al. (2007) Is the opening of a neighborhood full-service grocery store followed by a change in the food behavior of residents? Journal of Hunger and Environmental Nutrition, 2(1), pp. 3-18.
Wang, H., Qiu, F. and Swallow, B. (2014) Can community gardens and farmers' markets relieve food desert problems? A study of Edmonton, Canada. Applied Geography, 55, pp. 127-137.

Young, C.R., Aquilante, J.L., Solomon, S., Colby, L., Kawinzi, M.A., Uy, N. et al. (2013) Improving fruit and vegetable consumption among lowincome customers at farmers markets: Philly Food Bucks, Philadelphia, Pennsylvania, 2011. Preventing Chronic Disease, 10, e34.

\section{ACKNOWLEDGEMENTS}

We thank our colleagues who attended the Food Desert panel at the October 2016 American Collegiate Schools of Planning conference in Houston, Texas. The panel consisted of food planning scholars, practitioners and community members; discussion consisted of forty individuals representing geographic areas in California, Massachusetts, New York, Oregon, and Texas. The session was recorded with permission of attendees, transcribed and coded. Researchers used the insights from the expert panel to inform the regression analysis as well as interview questions for case study counties.

\section{Appendix: Interview Solicitation and Interview Questions}

\section{Dear [Public Health Department Official/ County Planning Office Official]}

I am [name, title and affiliation redacted to protect author's identity]. We are conducting interviews with planning and public health departments in counties that have a high percentage of the population living in a food desert, and lower than expected levels of diet-related disease (diabetes and obesity). As you know, the United States Department of Agriculture (USDA) has defined a food desert as a census tract with a substantial share of low-income residents who lack access to a supermarket or healthy, affordable food retail outlet. Yet, 'food deserts' often have their own well-adapted systems of street food, urban gardens and ride-shares to grocery outlets. From this study, we hope to learn about pathways to health in the food desert context.

Would you please let me know of a date and time within the next three weeks for a 15 minute, 5-question phone interview? Participation is voluntary, and we will send quotes to you for approval before we incorporate them into the final study and any resulting publications. I am including the phone interview questions for you to review below.

Thank you for your consideration.

Author, [phone number]

Question 1. How would you characterize your county's diet-related health?

- After briefly explaining the spatial data we have on your county, you are invited to reflect if it is representative of the county as a whole and matches your understanding 
Question 2. Can you think of some examples of actions taken in the county that may be contributing to improved health outcomes; i.e. low diabetes and lower rates of obesity than might be expected?

- E.g. sidewalks, walking trail, walk-to-school, WIC, county health fairs

Question 3. Tell us about the food planning and policy organizations and efforts in your county, if there are any.

- Who leads them?

- What are their main activities?

Question 4. Where do most residents obtain their food?

Prompts:

- Markets (farmers' market)

- Convenience stores/bodegas

- Garden private/Community garden

- Food bank

- Food/produce truck

- Buy directly from farms

- Roadside stands

- CSA

- Food delivery

- Small grocery stores

- Ride shares/carpool (public transit)

- Hunting/gathering - berry picking

- Large grocery store, brand-named

- Restaurants - fast food

Question 5. What are some explanatory reasons for resident health given the prevalence of food deserts in your county?

- Ask interviewee to reflect on their answers to questions 1 and 3. Do those answers adequately reflect healthy food policies in the county?

- Can he or she think of some examples of actions taken in the county that may be facilitating improved access to healthy foods in disadvantaged neighborhoods?

[Researcher summarizes response to see if it is correct after each question.]

\section{ACKNOWLEDGEMENTS}

The authors thank the numerous interviewees who graciously gave their time as well as Breana Inoshita, Abbie Schmidt and Tapinder Sidhu for their diligence in transcribing interviews. 